\title{
Spectrophotometric Analysis of Azithromycin and its Pharmaceutical Dosage Forms: Comparison between Spectrophotometry and HPLC
}

\author{
Nahid Sharmin, Nazia Sultana Shanta and Sitesh C. Bachar \\ Department of Pharmaceutical Technology, Faculty of Pharmacy, University of Dhaka \\ Dhaka-1000, Bangladesh
}

\begin{abstract}
A simple, reliable, precise and sensitive UV-spectrophotometric method was developed and validated for the estimation of azithromycin in pharmaceutical dosage form and compared with official USP 2010 method. The proposed method utilizes the oxidation of azithromycin with potassium permanganate to liberate formaldehyde. This formaldehyde reacts with acetone-ammonium reagent and produces yellow colored chromogen 3,5-diacetyl-2,6dihydrolutidine. The colored solution exhibited a maximum absorption at $412 \mathrm{~nm}$ which can be detected with UVspectrophotometer. The method was found linear over the concentration range $80 \%$ to $120 \%$ of the working concentration $\left(\mathrm{R}^{2}=0.999\right)$. The intra- and inter-day RSD $(\mathrm{n}=6)$ was $\leq 2.0 \%$. The developed method was validated according to ICH guidelines and values of accuracy, precision and other statistical analysis were found to be in good accordance with the prescribed values. The proposed method was successfully applied for determination of azithromycin and the results have been compared with HPLC and thus enabling the utility of this new method for routine analysis azithromycin in pharmaceutical dosage forms.
\end{abstract}

Key words: Azithromycin, UV spectrophotometer, chromogen, 3,5-diacetyl-2,6-dihydrolutidine, formaldehyde.

\section{INTRODUCTION}

Azithromycin ${ }^{1}$, a macrolide antibiotic that acts on Gram positive and Gram negative bacteria. It is chemically $^{2,3}(2 R, 3 S, 4 R, 5 R, 8 R, 10 R, 11 R, 12 S, 13 S, 14 R)$ -13-[(2,6-dideoxy-3-C-methyl-3-O-methyl- $\alpha$ - L-ribohexopyranosyl)-oxy]-2-ethyl-3,4,10-trihydroxy-3,5, 6,8,10,12,14-heptamethyl-11-[[3,4,6-trideoxy-3-(dimethyl-amino)- $\beta$ - $D$-xylo-hexopyranosyl]oxy]-1-oxa6-aza-cyclopentadecan-15-one dehydrate (Figure 1). ${ }^{2}$ It performs its antibacterial activity by inhibiting protein synthesis by binding reversibly to the ' $\mathrm{P}$ ' site of the $50 \mathrm{~S}$ ribosomal subunit of the bacteria. ${ }^{4,5}$ It is used to treat many adult and paediatric patients, ${ }^{6,7}$ in respiratory tract infection, ${ }^{8-10}$ skin, soft tissue infections, otitis media, ${ }^{8,11,12}$ sinusitis, pharyngitis, acute bronchitis, gastrointestinal infections, community-acquired pneumonia, cystic fibrosis, ${ }^{13,14}$ tonsilitis, ${ }^{15}$ anti-inflammatory in COPD patient, ${ }^{16}$ in

Correspondence to: Sitesh C. Bachar

E-mail: bacharsc63@gmail.com

Dhaka Univ. J. Pharm. Sci. 12(2): 171-179, 2013 (December)
P. falciparum malaria with other antimalarial drugs ${ }^{17}$ and typhoid fever. ${ }^{18,19}$ Azithromycin is derived from erythromycin; however it differs chemically from erythromycin in that a methyl substituted nitrogen atom is incorporated into the lactone ring and semisynthetic erythromycin derivative. ${ }^{20}$ It exhibits a more extensive spectrum of activity, greater acid stability, better oral bioavailability and more favorable pharmacokinetic behavior than erythromycin. $^{21}$ Its unique pharmacokinetic properties include extensive tissue distribution and high drug concentrations within cells. The most innovative feature is the efficacy and safety of a 3day oral regimen. ${ }^{22}$ The recommended dosage for azithromycin is $100-500 \mathrm{mg}$ per day.

Several methods have been reported for the determination of Azithromycin such as chromatographic method, spectrophotometric, spectrofluorimetric, voltammetric, and microbiological procedures. However, there is noticeable shortage of methods described in the literature for its 
determination in pharmaceutical dosage forms. Chromatographic methods developed for azithromycin quantization ${ }^{23-25}$ demand expensive equipment and could not be available in many laboratories. One electrochemical method has been described in literature, ${ }^{26}$ but it is based on reduction of azithromycin in strongly basic media at mercury electrode. Voltametric, chromatographic, and electrophoretic methods always use dedicated and expensive instruments that may not be available in some quality control laboratories in pharmaceutical industries. Microbiological methods are ensuring in vivo studies for potency determination of the antibiotics against sensitive organisms. Some of the reported spectrophotometric methods are associated with drawbacks such as decreased simplicity of the assay procedure, e.g., laborious extraction steps in ion-pair formation-based methods using halogenated solvents, which are dangerous to health and the environment.

The present study was designed to develop a new, simple, and specific spectrophotometric method for determination of the drug in bulk as well as in the commercial dosage forms available in the local markets, based on the reactivity of either the carbonyl ketone or the lactone ester functional groups. ${ }^{27,28}$

\section{MATERIALS AND METHODS}

Materials. Azithromycin active was obtained as a gift from Beximco Pharmaceuticals Ltd, Bangladesh. HPLC grade acetonitrile and methanol were obtained from Merck, Germany. Sodium-1octane sulphonic acid, ammonium dihydrogen phosphate and dipotassium hydrogen phosphate were purchased from BDH, UK. All other reagents were of analytical grade. HPLC (Agilent Technologies 1200 Series) was used which was equipped with a $210 \mathrm{~nm}$ detector and a $4.6 \mathrm{~mm} \times 25 \mathrm{~cm}$ column that contains 5 $\mathrm{mm}$ packing L1. Tablet Zithromax (250 mg) (Pfizer Inc. US) reference product and generic azithromycin tablets $(250 \mathrm{mg})$ were purchased from local market. Shimadzu UV 1615 spectrophotometer was used.

Preparation of standard azithromycin solution. Azithromycin $(250 \mathrm{mg})$ was accurately weighed and transferred to a $100 \mathrm{ml}$ volumetric flask. It was dissolved in glacial acetic acid $(20 \mathrm{ml}, 3 \mathrm{M})$, and diluted to $100 \mathrm{ml}$ with distilled water. An aliquot of $5.0 \mathrm{ml}$ was further diluted with water in $50 \mathrm{ml}$ volumetric flask, to obtain the final concentration of $0.25 \mathrm{mg} / \mathrm{ml}$.

Preparation of reagent (ammonium acetate acetone). Ammonium acetate-acetone reagent was prepared by dissolving ammonium acetate $(30 \mathrm{~g})$ in water $(50 \mathrm{ml})$. Acetone $(1.0 \mathrm{ml})$ was added, and the final volume was adjusted to $100 \mathrm{ml}$ with water, and stored in a refrigerator. Freshly prepared reagent was used in the study.

Oxidation of standard azithromycin solution, formaldehyde liberation and chromogen development. In a $10 \mathrm{ml}$ volumetric flask, standard solution of azithromcin $2 \mathrm{ml}$ (concentration 0.25 $\mathrm{mg} / \mathrm{ml}$ ) was taken and glacial acetic acid (3M) solution $1 \mathrm{ml}$ was added. Potassium permanganate solution $(0.25 \% \mathrm{w} / \mathrm{v}) 0.025 \mathrm{ml}$ was added. The reaction flask was heated on a water bath at $37^{\circ}$ for $10 \mathrm{~min}$ which resulted in the liberation of formaldehyde in situ. Excess of potassium permanganate was neutralized with oxalic acid (10\% $\mathrm{w} / \mathrm{v})$. Acetone containing reagent solution $(2 \mathrm{ml})$ was added to it and mixed thoroughly. The reaction flask was heated on a water bath at $37^{\circ}$ for $1 \mathrm{~min}$. The yellow colored chromogen was developed at this stage. The reaction mixture was cooled and the volume was adjusted up to the mark with distilled water. Absorbance of the colored solution was scanned on Shimadzu UV-visible spectrophotometer from $200 \mathrm{~nm}$ to $600 \mathrm{~nm}$ against reagent blank. Maximum absorbance was obtained at $412 \mathrm{~nm}$.

Preparation of standard curve of azithromycin. To prepare standard curve of Azithromycin, $0.4,0.8,1.0,2.0$ and $3.0 \mathrm{ml}$ of standard azithromycin solution were taken into a series of $10 \mathrm{ml}$ volumetric flask. A yellow colored chromogen had been developed following the proposed method in every case. Absorbance of the colored solution was measured at $412 \mathrm{~nm}$. The absorbance values were plotted against the concentrations on the graph. 
Assay of commercial dosage form by proposed method. Five market products of Azithromycin named B, E, I, R, and S were collected. Twenty tablets from each formulation were weighed accurately and powdered. The powder equivalent to $25 \mathrm{mg}$ Azithromycin was dissolved in glacial acetic acid (20 ml, $3 \mathrm{M}$ ), sonicated for $15 \mathrm{~min}$, and filtered. The residues were washed thoroughly with distilled water. The filtrate and washing was taken in a $100 \mathrm{ml}$ volumetric flask, and diluted up to the mark with the same solvent to produce the final concentration of $0.25 \mathrm{mg} / \mathrm{ml}$. The solution was taken $(2 \mathrm{ml})$ and glacial acetic acid (3M) solution $1 \mathrm{ml}$ was added. Then potassium permanganate solution $(0.25 \% \mathrm{w} / \mathrm{v}$, $0,025 \mathrm{ml}$ ) was added to it, heated at $37^{\circ} \mathrm{C}$, for 10 min. Excess potassium permanganate was neutralized with oxalic acid $(10 \% \mathrm{w} / \mathrm{v})$ and reagent solution (2 $\mathrm{ml})$ was added and mixed thoroughly. The reaction flask was heated on a water bath at $37^{\circ} \mathrm{C}$, for $1 \mathrm{~min}$, cooled and volume was adjusted up to the mark with distilled water. Absorbance of the solutions was measured against reagent blank in triplicate. Then \% content of azithromycin was measure by the following formula:

$\%$ Content $=($ Absorbance of sample $/$ Absorbance of standard $) \times 100$.

Sample solution stability. Potassium permanganate is a strong oxidizing agent and can unstable the color of the standard solution of azithromycin. Stability of the color has an effect on the absorbance of the solution. Unstable color gives substandard absorbance. Therefore, it was important to study the stability of the color of the chromogen.

To observe the effect of light on the stability of the chromogen, two volumetric flasks containing similar concentrations of azithromycin were taken and chromogen was developed following the procedure described above. Then one chromogen solution was kept in strong daylight and the other was kept in a dark place for twelve hours. Absorbance of the solutions was taken every two hours.

Effect of temperature on sample solution. To examine the effect of temperature on the absorbance of azithromycin sample solution, a volumetric flask containing standard azithromycin solution was placed in a water bath. The temperature of the water bath was varied from 25 to $60^{\circ} \mathrm{C}$. Absorbance of the solution was taken at different temperature and was plotted.

Effect of shaking time on sample solution. Shaking influences the complete and uniform mixing of a heterogenous mixture. In the proposed method, complete liberation of formaldehyde from azithromycin needs proper shaking of azithromycin solution. So the effect of shaking time was observed. Standard solution of azithromycin was shaken for 1 , 2, 3, 4, 5, 6 and 7 minutes. Their corresponding absorbance were taken and plotted.

\section{Assay by USP 2010 Official method}

Preparation of mobile phase. Dibasic potassium phosphate $4.4 \mathrm{~g}$ and $500 \mathrm{mg}$ of sodium 1-octanesulfonate were transferred to a $1000 \mathrm{~mL}$ volumetric flask, and diluted with water to volume. It was adjusted with phosphoric acid to a $\mathrm{pH}$ of $8.20 \pm 0.05$. Then mobile phase was prepared by filtering and degassing the mixture of acetonitrile, octane sulfonate buffer and methanol in a ratio of $45: 40: 15 .^{29}$

Preparation of diluent A. At first, $1.7 \mathrm{~g}$ of monobasic ammonium phosphate was transferred to a 1-L volumetric flask and diluted with water to volume. Then $\mathrm{pH}$ was adjusted to $10.00 \pm 0.05$ with ammonium hydroxide.

Then diluents A was prepared by mixing ammonium phosphate buffer $\mathrm{pH} 10$, methanol, and acetonitrile in a ratio of $35: 35: 30{ }^{29}$

Preparation of standard azithromycin solution. First of all, standard azithromycin solution was prepared by taking $20 \mathrm{mg}$ of USP azithromycin $\mathrm{RS}$ in a $50 \mathrm{ml}$ volumetric flask. Then Diluent A was added up to the mark and sonicated to obtain a solution having a concentration of $0.4 \mathrm{mg}$ of azithromycin per $\mathrm{mL}$.

Preparation of sample solution. Five market products of Azithromycin named $\mathrm{B}, \mathrm{E}, \mathrm{I}, \mathrm{R}$, and $\mathrm{S}$ were collected as before. Twenty tablets from each formulation were weighed and finely powdered. An accurately weighed portion of the powder, equivalent to about $667 \mathrm{mg}$ of azithromycin was transferred to a $200 \mathrm{ml}$ volumetric flask. Diluent A $(75 \mathrm{ml})$ was 
added, and sonicated for not less than 15 minutes. The solution was allowed to equilibrate to room temperature, diluted with Diluent A to volume. The solution $(6.0 \mathrm{ml})$ was transferred to a $50 \mathrm{ml}$ volumetric flask, diluted with Diluent A to volume, and mixed to obtain a solution having a nominal concentration of $0.4 \mathrm{mg}$ of azithromycin per $\mathrm{ml}$ and passed through a filter having a porosity of $0.45 \mu \mathrm{m}$. Sample solutions of five market products were prepared following this method.

Chromatographic system. The liquid chromatograph was equipped with a $210-\mathrm{nm}$ detector and a $4.6 \mathrm{~mm} \times 25 \mathrm{~cm}$ column that contains $5-\mathrm{mm}$ packing L1. The flow rate was about $1.5 \mathrm{ml}$ per minute and run time was 30 minutes. The column was maintained at a constant temperature of about $50^{\circ} \mathrm{C}$. The HPLC was run and the equilibrium condition of the column was checked by injecting standard solution $(50 \mu \mathrm{l})$ repeatedly until the relative standard deviation is not more than $2 \%$ for six consecutive injections. ${ }^{29}$

Assay procedure. Equal volumes (about $50 \mu \mathrm{l}$ ) of the azithromycin standard preparation and the sample preparations (five marketed products) were separately injected into the chromatograph, and the peak area responses $(n=3)$ were measured for all the peaks. Then $\%$ content of azithromycin was calculated by using the following formula:

$\%$ Content $=($ Peak area of sample $/$ Peak area of standard) $\times 100$

\section{Analytical method validation}

Accuracy. The accuracy of an analytical method is the closeness of the test results obtained by that method to the true value. ${ }^{30}$ Accuracy of the analytical procedure was established at three concentration levels $(80,100$ and $120 \%)$ of the working standard solution $(n=3)$ by standard addition method. From this sample solution $2.0 \mathrm{ml}$ was transferred to three $10 \mathrm{ml}$ volumetric flasks and to these flasks $0.8,1.0$ and $1.2 \mathrm{ml}$ of standard solution of azithromycin were added respectively. The solutions were then oxidized and colors were developed following the proposed method. The colored solutions were analyzed as before. The $\%$ recovery and $\%$ RSD were calculated.

Precision. The precision of an analytical procedure expresses the closeness of agreement between a series of measurements obtained from multiple sampling of the same homogeneous sample under the prescribed conditions. ${ }^{31}$ Precision can be measured as repeatability (Intra-day precision), reproducibility and intermediate precision (Inter-day precision). Because reproducibility refers to the use of the same analytical procedure in different laboratories, in this work only repeatability and intermediate precision were studied. ${ }^{32}$

Repeatability (Intra-day precision). The repeatability of the developed UV method was determined by preparing the standard solutions at three concentrations $(20,40$ and $50 \mu \mathrm{g} / \mathrm{ml})$ and six replicates $(n=6)$ each on same day. The $\%$ RSD of the results was calculated.

Intermediate precision (Inter-day precision). The intermediate precision was determined by preparing standard solutions at three concentrations $(20,40$ and $50 \mu \mathrm{g} / \mathrm{ml})$ over three consecutive days $(\mathrm{n}=3)$. The solutions were oxidized and color was developed as the proposed method. Then absorbance was taken. The $\%$ RSD value was calculated.

Linearity and range. Linearity is determined experimentally by analysis of a series of standards at five different concentrations that span $80-120 \%$ of the expected working range of the assay. ${ }^{32}$ Five standard solutions of azithromycin were prepared covering a concentration range of $80-120 \%$ of the working standard solution. Appropriate amounts of the standard solution were diluted with distilled water to yield concentrations of 20,22.5, 25, 27.5 and 30 $\mu \mathrm{g} / \mathrm{ml}$. The solutions were oxidized and chromogen was developed as the proposed method. Absorbance of the colored solutions was plotted against theoretical concentration. The linearity was evaluated by calculation of the correlation coefficient obtained from linear regression analysis.

Limit of detection (LOD) and quantification (LOQ). LOD was determined using the signal-to noise ratio, and then comparing the test results from 
the samples with known concentrations. The analyte concentration that produced a signal-to-noise ratio of 3:1 was accepted as LOD.

Limit of quantification (LOQ) is defined as the lowest concentration of the analyte that can be determined with acceptable precision and accuracy under the stated experimental conditions.

Robustness. Robustness of an analytical method is a measure of its capacity to remain unaffected by small but deliberate variations in method parameters and provides an indication of its reliability during normal usage. The robustness of the proposed method was determined by analyzing the same standard solution (concentration $50 \mu \mathrm{g} / \mathrm{ml}$ ) in two different UV-spectrophotometers (Shimadzu 1615 and Shimadzu 1700) and by preparing the standard solution (concentration $50 \mu \mathrm{g} / \mathrm{ml}$ ) in two different volumetric flasks $(50$ and $100 \mathrm{ml}$ ). The result was expressed in \% RSD.

Placebo interference. Placebo is mixture of excipients without any drug. It has no pharmacological effect. Placebo sample solution was prepared and assayed in the same manner as that of proposed method and absorbance was measured. Absorbance of the solution was measured against reagent blank.

\section{RESULTS AND DISCUSSION}

Azithromycin is characterized by the presence of lactone ester and ketone groups, isosterically replaced by a tertiary amine. Therefore, this compound offers excellent model for a comparison of the reactivity of lactone ester and/or ketone derivatives with a reagent such as ammonium acetate-acetone, which should lead to the development of a method for their determination.

General description of the reaction and its products. For determining azithromycin in tablet dosage form, a color reaction is described that depends on the formation of diacetyldihydrolutidine by a condensation reaction between acetone and formaldehyde in the presence of excess ammonium salt. This reaction is similar to the Nash method which is based on the Hantzsch pyridine synthesis where formaldehyde reacts with a reagent consisting of acetone and concentrated ammonium acetate. ${ }^{28}$ Based on this method, when traces of formaldehyde are added to approximately neutral solutions of acetone and ammonium salt, a yellow colored chomogen gradually develops owing to the formation of diacetyldihydrolutidine. This yellow colored chromogen named as 3,5-diacetyl-2,6-dihydrolutidine exhibits fluorescence. ${ }^{33}$

Development of the analytical method. The colored solution obtained by the oxidation of azithromycin followed by reaction with reagent solution gave maximum absorption or $\lambda_{\max }$ at 412 $\mathrm{nm}$. The absorbance of the standard solution was 0.301 and concentration was $50 \mu \mathrm{gm} / \mathrm{ml}$.

Standard curve. The standard curve was constructed by plotting the absorbance against concentration. The linear regression equation obtained was $\mathrm{y}=0.006 \mathrm{x}+0.004$ with co-relation coefficient 0.999. Beer's law was obeyed in the concentration range of $10-75 \mu \mathrm{g} / \mathrm{ml}$.

Assay of market preparation by official USP 2010 and proposed method. The percent content of azithromycin was determined by measuring the absorbance and peak area responses of market samples by the proposed method and official method respectively (Table 1). The percent content from the commercial preparations were found between 98.56 $100.11 \%$ by the proposed method. While the percent content were found between $101.56-104.3 \%$ by the official USP 2010 method. The results were found within the limit $95-105 \%$ for both methods. Therefore, it can be said that the result of proposed method matched to that of USP official method.

Table 1. Assay results of marketed formulations by official USP 2010 and proposed method

\begin{tabular}{lcc}
\hline Products & $\begin{array}{c}\text { \% content measured } \\
\text { by official USP 2010 } \\
\text { method }(\mathrm{M} \pm \mathrm{SD})\end{array}$ & $\begin{array}{c}\text { \% content measured by } \\
\text { proposed method } \\
(\mathrm{M} \pm \mathrm{SD})\end{array}$ \\
\hline $\mathrm{B}$ & $102.7 \pm 0.001$ & $100.11 \pm 0.191$ \\
$\mathrm{E}$ & $104.3 \pm 0.009$ & $98.67 \pm 0.332$ \\
$\mathrm{I}$ & $103.1 \pm 0.001$ & $99.44 \pm 0.191$ \\
$\mathrm{R}$ & $101.56 \pm 0.002$ & $98.56 \pm 0.383$ \\
$\mathrm{~S}$ & $101.74 \pm 0.001$ & $99.45 \pm 0.507$ \\
\hline
\end{tabular}


Method validation. Accuracy of the proposed method was evaluated by recovery studies of the drug. The average recovery was 100.1, 99.92 and 99.9\% (Table 2) for concentration levels 80, 100 and $120 \%$ of the working concentration respectively. For the above three concentration levels \% RSD were within $0.122-0.189$, which is satisfactory. The percent RSD was found in the range of 0.47 - 0.82 for intra-day precision (Table 3) and $0.013-0.014$ for inter-day precision (Table 4) which indicate that the intermediate precision of the proposed method is acceptable.

The linearity calibration curve showed linear response over the range of concentration used and the correlation co-efficient was found to be 0.999 , which was close to unity (Figure 3). LOD and LOQ were found to be 0.6 and $1.98 \mu \mathrm{g} / \mathrm{ml}$, respectively, indicating high method sensitivity. The results of robustness study varied very slightly. The mean of $\%$ recovery was 99.946 and \% RSD was 0.065 .

Table 2. Determination of accuracy.

\begin{tabular}{lccccc}
\hline $\begin{array}{l}\text { Concentration } \\
\text { level }\end{array}$ & $\begin{array}{c}\text { Amount of sample } \\
\text { Azithromycin }(\mu \mathrm{g} / \mathrm{ml})\end{array}$ & $\begin{array}{c}\text { Amount of pure } \\
\text { drug added } \\
(\mu \mathrm{g} / \mathrm{ml})\end{array}$ & $\begin{array}{c}\text { Amount of Azithromycin } \\
\text { recovered }(\mu \mathrm{g} / \mathrm{ml})(\mathrm{M} \pm \\
\mathrm{SD})(\mathrm{n}=3)\end{array}$ & $\%$ RSD & \% Recovery \\
\hline $80 \%$ & 50 & 20 & $20.02 \pm .03$ & 0.149 & 100.1 \\
$100 \%$ & 50 & 25 & $24.98 \pm .03$ & 0.122 & 99.92 \\
$120 \%$ & 50 & 30 & $29.97 \pm .05$ & 0.189 & 99.9 \\
\hline
\end{tabular}

Table 3. Repeatability (Intra-day precision)

\begin{tabular}{cccc}
\hline $\begin{array}{c}\text { Conc. } \\
(\mu \mathrm{g} / \mathrm{ml})\end{array}$ & $\begin{array}{c}\text { Absorbance } \\
(\mathrm{n}=6)\end{array}$ & Mean $\pm \mathrm{SD}$ & \% RSD \\
\hline 20 & 0.128 & $0.127 \pm 0.00147$ & 0.8235294 \\
& 0.127 & & \\
& 0.126 & & \\
& 0.128 & & \\
& 0.127 & & \\
& 0.129 & & \\
40 & 0.244 & $0.243 \pm 0.00126$ & \\
& 0.243 & & \\
& 0.242 & & \\
& 0.244 & & \\
& 0.241 & & \\
& 0.244 & & \\
50 & 0.3 & $0.3 \pm 0.00141$ & \\
& 0.299 & & \\
& 0.301 & & \\
& 0.3 & & \\
& 0.302 & & \\
& 0.298 & & \\
\hline
\end{tabular}

Table 4. Intermediate precision (Inter-day precision).

\begin{tabular}{cccc}
\hline $\begin{array}{c}\text { Theoretical } \\
\text { conc. }(\mu \mathrm{g} / \mathrm{ml})\end{array}$ & \multicolumn{3}{c}{ Interday Precision $(\mathrm{n}=3)$} \\
\cline { 2 - 4 } & $\begin{array}{c}\text { Conc. }(\mu \mathrm{g} / \mathrm{ml}) \\
(\mathrm{M} \pm \mathrm{SD})\end{array}$ & \% Recovery & \%RSD \\
\hline 20 & $19.96 \pm 0.02$ & 99.81481 & 0.034 \\
40 & $39.66 \pm 0.01$ & 99.16667 & 0.030 \\
50 & $50.14 \pm 0.006$ & 100.2963 & 0.013 \\
\hline
\end{tabular}

On the other hand, same concentration (50 $\mu \mathrm{g} / \mathrm{ml}$ ) of the standard solution was prepared in two volumetric flasks and their absorbance values were measured on the same day. No noticeable change in absorbance was observed. It indicates that the method was robust enough to analyze azithromycin in tablet dosage form. Placebo solution gave an absorbance 0.001 when measured at $412 \mathrm{~nm}$. Therefore, it is revealed that effect of excipient on the absorbance of azithromycin is negligible.

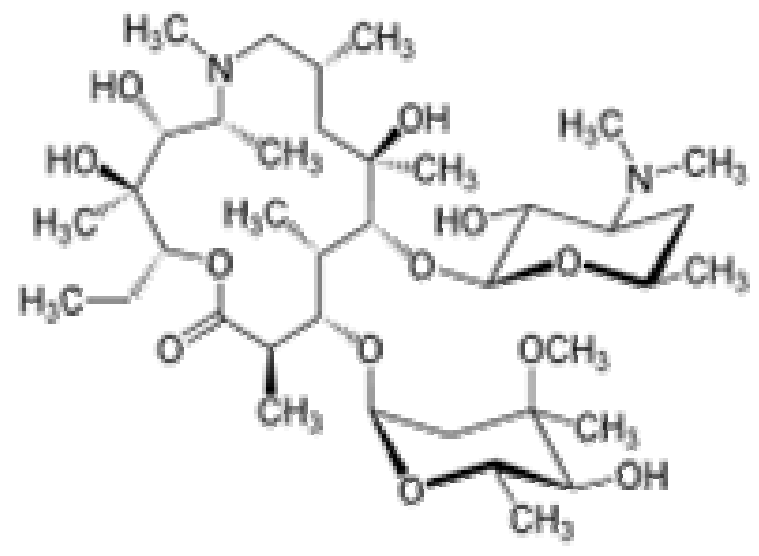

Figure 1. Chemical structure of Azithromycin 


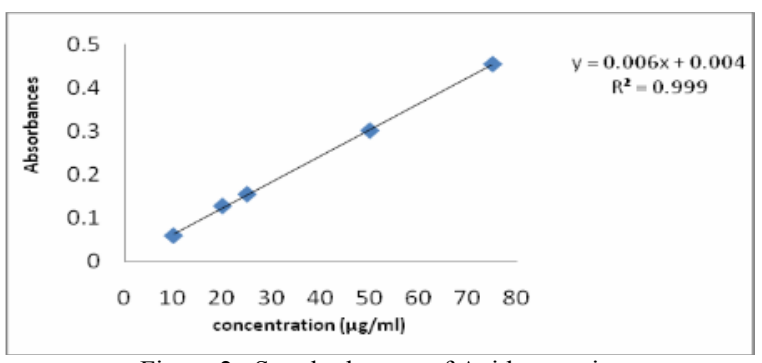

Figure 2. Standard curve of Azithromycin.

Stability of sample solution. Potassium permanganate is a strong oxidizing agent. So it can destroy diacetyldihydrolutidine, the chromogen, either by complete breakdown of the molecule or by oxidation to the colorless diacetyldihydrolutidine. There is also a chance of fading of color by daylight, due to the dissolved oxygen. Light and darkness gave variable influence on stability of the color of azithromycin standard solution. In daylight strong yellow color was observed for two hours. Then color

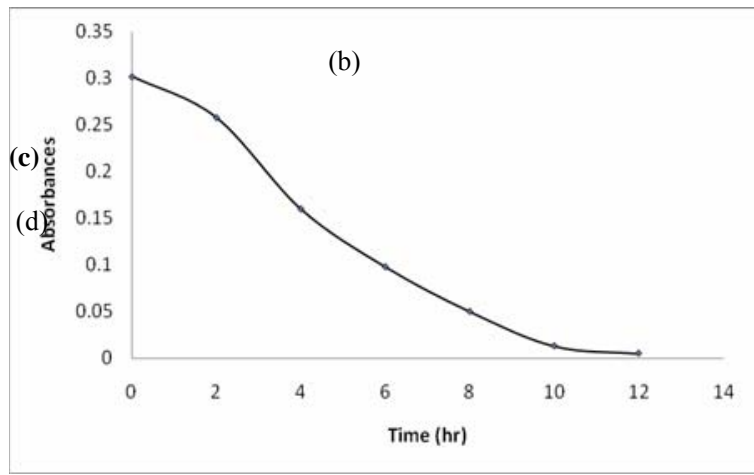

(a)

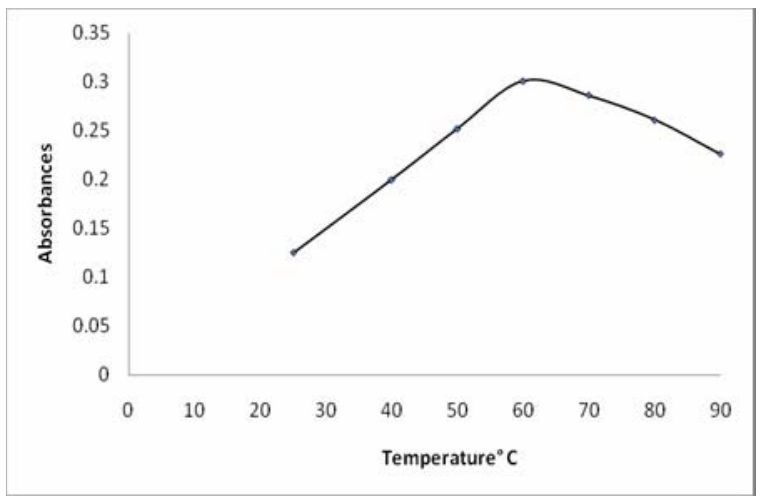

(c) started becoming fade in the following four hours. After six hour it became almost colorless [Figure 4(a)]. While in darkness, a strong stable yellow color was observed for six hours. Then after 8 hours it became light yellow [Figure 4(b)]. Study on effect of temperature on chromogen solution showed that,

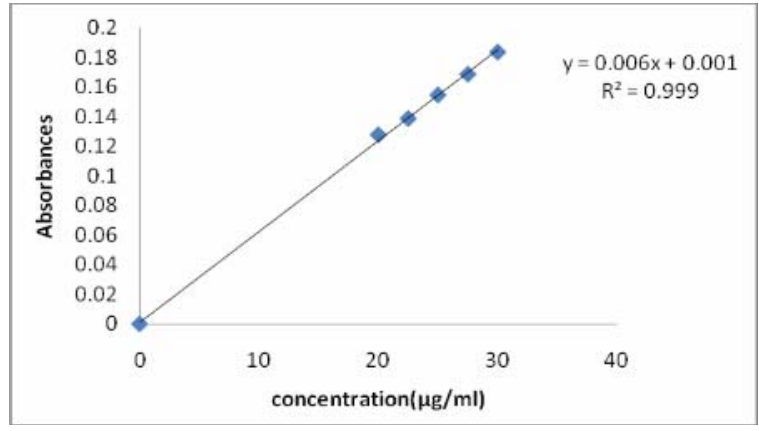

Figure 3. Graphical representation of linearity.

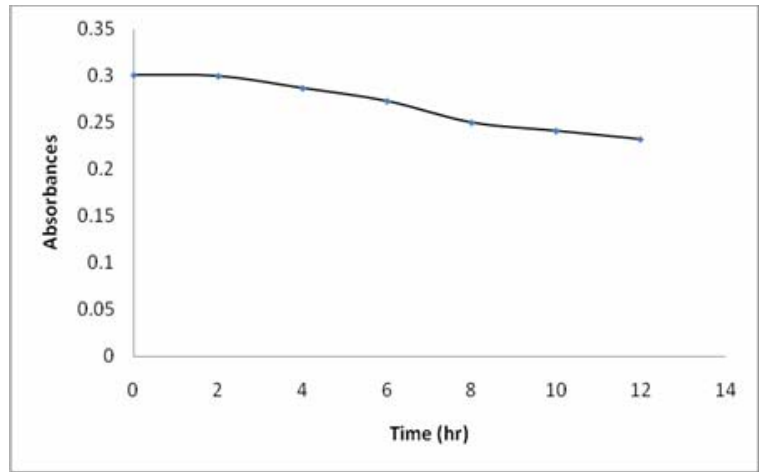

(b)

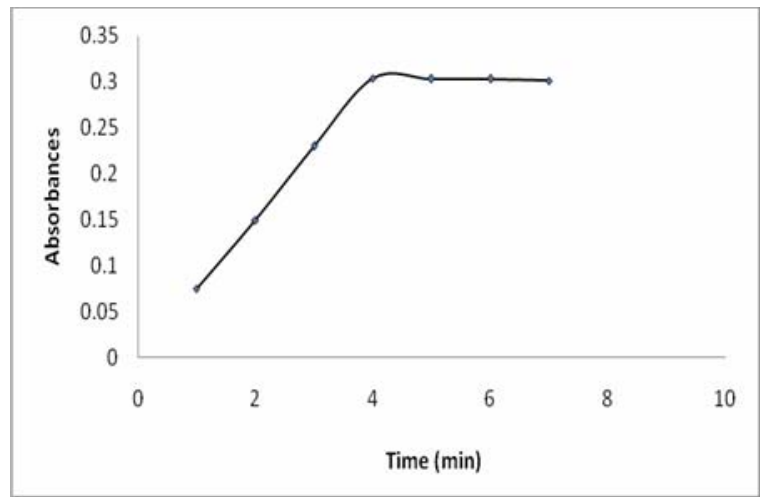

(d)

Figure 4. Effect of various parameters on the stability of the color of chromogen; (a) daylight (b) darkness (c) reaction temperature and (d) shaking time. 
color intensity i.e. absorbance was increased with temperature up to $60^{\circ} \mathrm{C}$. Then intensity decreased with temperature [Figure 4(c)]. From Figure 4(d), it is evident that absorbance increased with shaking time and maximum absorbance was obtained at 4 minute. After that, absorbance decreased and finally became flat. This indicates the completion of reaction.

\section{CONCLUSION}

Many pharmaceutical companies in our country do not have sufficient instruments to carry out the assay of azithromycin in laboratory. Here a very simple, sensitive, cheap and reliable method of determining azithromycin has been described using UV spectrophotometer. The method has been validated in terms of accuracy, precision, linearity, robustness and repeatability and found to be worthy to carry out assay and detection of azithromycin in any pharmaceutical dosage form.

\section{ACKNOWLEDGEMENT}

Authors are highly thankful to Beximco Pharmaceuticals Ltd, Bangladesh for providing gift sample of Azithromycin. We acknowledge Department of Pharmaceutical Technology, Faculty of Pharmacy, University of Dhaka for providing the facilities to complete the work.

\section{REFERENCES}

1. Budavari, S. Eds. 1996. In: The Merck Index. Merck and Co. Inc., Whitehouse Station, N. J., 12 ed, p-948.

2. Reynolds, J.E.F. 1999. In: Martindale: The Extra Pharmacopoeia. The Pharmaceutical Press, London, 32 ed, p-155.

3. United States Pharmacopoeia XXIV, NF XIX, 2000. The USP convention, Inc, Rockville, MD, $25^{\text {th }} \mathrm{ed}, \mathrm{p}-185$.

4. Sharma, H.L. and Sharma, K.K. 2008. In: Principles of pharmacology. Revised reprint-2008. Paras Medical Publisher, Hyderabad. p.761-762.

5. Goldman, R.C., Fesik, S.W. and Doran, C.C. 1990. Role of protonated and neutral forms of macrolides in binding to ribosomes from Grampositive and Gram-negarive bacteria. Antimicrob. Agents Chemother. 34, 426-431.
6. Treadway, G. and Reisman, A. 2001. Tolerability of 3-day, once-daily azithromycin dihydrate suspension versus standard treatments for community-acquired paediatric infectious diseases. Int. J. Antimicrob. Agents. 18, 427-431.

7. Pacifico, L. and Chiesa, C. 2002. Azithromycin dihydrate in children: A critical review of the evidence. Curr. Therapeutic. Res. 63, (1), 54-76.

8. Treadway, G., Pontani, D. and Reisman, A. 2002. The safety of azithromycin dihydrate in the treatment of adults with community acquired respiratory tract infections. Int. J. Antimicrob. Agents. 19, 189-194.

9. Ferrara, A., Santos, C.D. and Cimbro, M. 1996. Comparative antimicrobial activity and post-antibiotic effect of azithromycin, clarithromycin and roxithromycin against some respiratory pathogens. Int. J. Antimicrob. Agents. 7, 181-186.

10. Hoepelman, I., Mollers, M. and Schied, M. 1998. A short (3day) course of azithromycin dihydrate tablets versus a 10-day course of amoxycillin-clavulanic acid (co-amoxiclav) in the treatment of adults with lower respiratory tract infections and effects on long-term outcome. Int. J. Antimicrob. Agents. 9, 141-146.

11. Block, S., Arrieta, A. and Seibel, M. 2003. Single-Dose (30 $\mathrm{mg} / \mathrm{kg}$ ) azithromycin dihydrate compared with 10-day amoxicillin/clavulanate for the treatment of uncomplicated acute otitis media: A double-blind, placebo-controlled, randomized clinical trial. Curr. Therapeutic. Res. 64(A), $30-42$.

12. Rothermel, C. 2003. Single-dose azithromycin dihydrate for acute otitis media: A pharmacokinetic/pharmacodynamic rationale. Curr. Therapeutic Res. 64(A).A4-A15.

13. Kabra, S., Pawaiya, R. and Lodha, R. 2010. Long-term daily high and low doses of azithromycin dihydrate in children with cystic fibrosis: A randomized controlled trial. J. of Cystic Fibrosi .9, 17-23.

14. Yousef. A. and Jaffe, A. 2010. The role of azithromycin dihydrate in patients with cystic fibrosis. Paedia. Respiratory Reviews. 11, 108-114.

15. Baschiera, F. and Fornai, M. 2002. Improved tonsillar disposition of azithromycin dihydrate following a 3-day oral treatment with $20 \mathrm{mg} / \mathrm{kg}$ in paediatric patients. Pharmacol. Res. 46, 95-100.

16. Parnham, M. 2005. Modulation of neutrophil and inflammation markers in chronic obstructive pulmonary disease by short-term azithromycin dihydrate treatment. Eur. J. Pharmaco.517, 132-143. 
17. Nakornchai, S. and Konthiang, P. 2006. Activity of azithromycin dihydrate or erythromycin in combination with antimalarial drugs against multidrug-resistant Plasmodium falciparum in vitro. Acta Tropica. 100, 185-191.

18. Ferrera, K. and Bomasang, E. 2004. Azithromycin dihydrate versus first line antibiotics in the therapeutic management of documented cases of typhoid fever: A metaanalysis. Phil. J. Microbio. Infectious Diseases, 33, 163-168.

19. Butler, T., Sridhar, C., Dagac, M. and Pathak, K. 1999. Treatment of typhoid fever with azithromycin dihydrate versus chloramphenicol in a randomized multicentre trial in India. J. Antimicrob. Chemother. 44, 243-250.

20. Sultana, N., Sayeed Arayne, M., Hussain, F. and Fatima, A. 2006. Degradation studies of azithromycin and its spectophotometric determination in pharmaceutical dosage forms. Pak. J. Pharm. Sci. 19, 94-98.

21. Lode, H., Borner, K., Koeppe, P. and Schaberg, T. 1996. Azithromycin: review of key chemical, pharmacokinetic and microbiological features. J. Antimicrob. Chemother. 37, 1-8.

22. Dunn, C.J. and Barradell, L.B. 1996. Azithromycin: a review of its pharmacological properties and use as 3-day therapy in respiratory tract infections. Drugs. 51, 483-505.

23. Kanfer, I., Skinner, M.F. and Walker, R.B. 1998. Analysis of macrolide antibiotics. J. Chromatogr. A. 821, 255-286.

24. Horie, M., Saito, K., Ishii, R., Yoshida, T., Haramaki, Y. and Nakazawa, H. 1998. Simultaneous determination of five macrolide antibiotics in meat by high-performance liquid chromatography. J. Chromatogr. A. 812, 295-302.

25. Kamau, F.N., Chepkwony, H.K., Ngugi, J.K., Debremaeker, D., Roets, E. and Hoogmartens, J. 2002. Isocratic liquid chromatographic method for the analysis of azithromycin and its structurally related substances in bulk samples. $J$. Chromatog. Sci. 40, 529-533.
26. Gandhi, R., Kaul, C.L. and Panchagnula, R. 2000. Validated LC method for in vitro analysis of azithromycin using electrochemical detection. J. Pharm. Biomed. Anal. 23, 1073-1079.

27. Praveen, P. Sai., Anupama, B., Jagathi, V. and Rao, D. 2010. Spectrophotometric determination of Tolperisone using 2, 4dinitrophenylhydrazine reagent. Int. J. Res. Pharm. Sci. 01, 317-320.

28. Compton, B. J. and Purdy, W. C. 1980. The mechanism of the reaction of the Nash and the Sawicki aldehyde reagent. Can. J. Chem. 58, 2207-2211.

29. Azithromycin Tablets Monograph, In Reference Standards, In “The United States Pharmacopeial Convention". 2012. Revision Bulletin. Inc, Rockville. MD, p.1-2.

30. Validation of compendial methods, In "United States Pharmacopoeia 29, NF 24", 2006. The USP convention, Inc, Rockville. MD, p. 3050

31. Shah. V. and Raj, H. 2012. Development and validation of spectroscopic method for simultaneous estimation of cefixime trihydrate and azithromycin dihydrate in combined dosage form. Int. J. Pharm. Bio. Sci., 3, 14-25.

32. Kulikov, A.U. and Verushkin, A. G.2004. Development and validation of a micellar liquid chromatographic method with UV detection for determination of azithromycin in tablets and capsules. Chromatographia, 60, 33-38.

33. Suhagia, B.N., Shah,S. A., Rathod, I.S., Patel, H.M. and Doshi, K.R. 2006. Determination of azithromycin in pharmaceutical dosage forms by spectrophotometric method. Indian J. Pharm. Sci. 68, 242-245. 